Institute of $\mathbf{F}_{\text {ood and }} \mathbf{A}_{\text {gricultural }} \mathbf{S}_{\text {ciences }}$

\title{
Jaguar: Another Threatened Panther ${ }^{1}$
}

\section{Anthony J. Novack and Martin B. Main ${ }^{2}$ \\ DESCRIPTION}

Jaguars are massive cats, much larger than even the biggest Florida panther. The size of these cats varies regionally. The largest jaguar ever recorded was a male that weighed 149 kilograms, more than 300 pounds. To put this weight into perspective, this animal was about as big as a defensive lineman for the National Football League's Jacksonville Jaguars. Most male jaguar weigh between 50-100 kilograms (110-220 lbs). Females will be about one-fifth smaller, and range in weight from 35-80 kg (75-175 lbs). In comparison, male Florida panthers weigh $45-70 \mathrm{~kg}$ (100-155 lbs) and female panthers weigh $30-45 \mathrm{~kg}$ (65-100 lbs).

From tip of the tail to the point of its nose, a jaguar typically measures between 1.6-2.4 m (5.3-7.9 $\mathrm{ft}$ ), with a shoulder height of 68-75 cm (27-30 in). Florida panthers are similar in length and height, and typically vary in length from 1.8-2.2 m (5.9-7.2 ft) and range in height at the shoulder from $60-70 \mathrm{~cm}$ (24-28 in).

Consequently, the big difference between jaguar and the Florida panther is in body mass. The jaguar is more stoutly built than a panther, with a broader head, larger paws, and a shorter tail. A deep chest and barrel-shaped body are kept in motion by short, powerful limbs designed to take down large powerful prey in heavy cover, such as white-lipped peccaries and white-tailed deer.

The fur of most jaguars appears buffy yellow or as a golden orange hue that shades into yellow. The jaguar coat, or pelage, on the upper part of the body is covered in spots. These spots are small and solid on the head and shoulders, but take the form of broken rings, called rosettes, on the back and flanks. Each rosette encircles an area with zero to three dots. The overall pattern of these rosettes is unique to each individual jaguar, just like fingerprints are to people. Underparts are white, and marked with black splotches or bars. This pelage is cryptic and camouflages the cat when it lies motionless under broken sunlight.

Occasionally, jaguar are black, or nearly solid black, in color, an inherited genetic condition known as melanism. These "black panthers" still have their spots and if a person looks closely, the darker rosettes can be seen in contrast from the rest of the fur. Melanism has not been officially documented in the Florida panther.

1. 1. This document is Fact Sheet WEC 167, one of a series of the Department of Wildlife Ecology \& Conservation, Florida Cooperative Extension Service, Institute of Food and Agricultural Sciences, University of Florida. Originally published in cooperation with the Florida Fish and Wildlife Conservation Commission's Nongame Wildlife Program. Publication date:May 2003. Please visit the Edis Web site at http://edis.ifas.ufl.edu

2. Martin B. Main, wildlife extension specialist; Anthony J. Novack, former wildlife research assistant, Department of Wildlife Ecology and Conservation, Institute of Food and Agricultural Sciences, University of Florida, Gainesville FL 32611-0304.

The Institute of Food and Agricultural Sciences is an equal opportunity/affirmative action employer authorized to provide research, educational information and other services only to individuals and institutions that function without regard to race, color, sex, age, handicap, or national origin. For information on obtaining other extension publications, contact your county Cooperative Extension Service office. Florida Cooperative Extension Service/Institute of Food and Agricultural Sciences/University of Florida/Christine Taylor Waddill, Dean. 


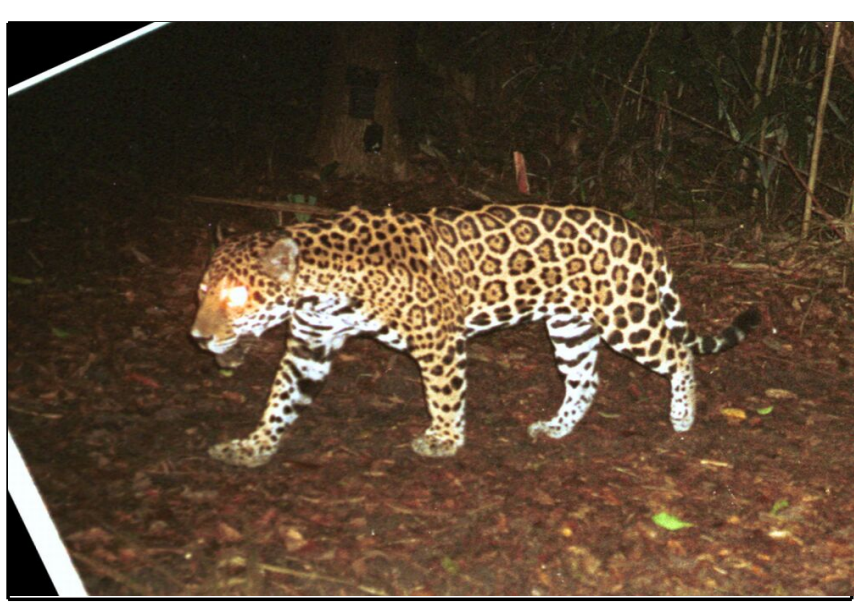

Figure 1. The jaguar (Panthera onca), also called panther, tigre or onza, is the largest and most powerful cat in the western hemisphere. Much like its relative the Florida panther ( Puma concolor), this cat is threatened by human activities.

\section{DISTRIBUTION}

Jaguars have not been found in Florida since Prehistoric times. When Spaniards first discovered Florida, the northern limit of the jaguars range extended into Texas, New Mexico and Arizona. Further south, the jaguar was found throughout Mexico, Central and South America, all the way to northern Argentina. By the 1980s, the jaguars range was reduced by two-thirds in North and Central America and, within $75 \%$ of its present range, the jaguar has been reduced or greatly reduced in numbers. Although the jaguar has been virtually eliminated from the United States, photographs of a jaguar in Arizona were documented during 2002

\section{HABITAT}

Jaguar require forest cover and can be found in almost any tropical forest type including evergreen forest, deciduous forest, and thornscrub. Jaguar are rarely found in grasslands devoid of trees.

Additionally, this cat seems to prefer areas near water, such as the thick forest types found along rivers and floodplains.

\section{DIET}

Like all cats, jaguars are strictly carnivorous, which means they only eat meat. They are not finicky eaters, with more than 89 species of animals recorded as prey for jaguar. These large cats prefer to eat other mammals, but have also been reported to eat birds, fish, snakes, and even caimans (a type of crocodile) and sea turtles. When possible, jaguars prefer to hunt large prey, such as white-tailed deer, collared peccaries, or large tropical rodents. Where these prey are available, a jaguar may only need to eat once or twice per week. On occasion, jaguar will attack cattle or other livestock, thereby causing conflicts with livestock owners.

\section{BEHAVIOR AND HOME RANGE}

Jaguars are most active at night, early morning, and late evening. Like most wild cats, jaguars live alone and only come together for brief periods to mate. Males roam over large territories that can encompass $50-139 \mathrm{~km}^{2}\left(19-53 \mathrm{mi}^{2}\right)$ in many regions. Females have smaller territories, usually between 26-97 $\mathrm{km}^{2}$ (10-37 $\mathrm{mi}^{2}$ ). Several females may reside within the territory of one male, with which they breed. The resident male fiercely defends his territory from other male jaguar to ensure that the females in his territory mate only with him. As with other large wildcats, young males must roam large areas avoiding resident males. These young males, often referred to as "satellite" or "transient" males, must keep up this wandering existence until a resident male dies and leaves a territory vacant or they defeat the resident male in battle and gain control of his territory - and his females.

Interestingly, Florida panthers actually use much larger home ranges than jaguar. Differences in home range size are related to habitat quality. Whereas the tropical forests in which jaguar live provide excellent habitat and abundant prey, the scattered remaining forests available to panthers in south Florida offer relatively poor habitat in comparison. Consequently, the home range of Florida panthers is considerably larger with male home ranges averaging about 520 $\mathrm{km}^{2}\left(200 \mathrm{mi}^{2}\right)$ and home ranges of female panthers averaging about $195 \mathrm{~km}^{2}\left(75 \mathrm{mi}^{2}\right)$. For both jaguar and panthers, therefore, the size of the home range is influenced by the availability of high quality habitat and prey, and this is particularly important for females raising kittens. 


\section{REPRODUCTION}

The breeding season varies between locales and can occur during any time of the year. Pregnancy lasts about 100 days. The female will give birth to a litter of 1-4 cubs, usually two. Until the cubs are old enough to travel with her, the mother will keep them hidden in a secluded den site such as a cave or abandoned mine. The cubs remain with the mother until they are 1.5-2 years old. Males have no part in raising cubs.

\section{LEGAL STATUS}

The Convention for the International Trade in Endangered Species (CITES) listed the jaguar in Appendix I, which means that it is illegal to trade in jaguar skins or parts, and that the transport of such items across country borders is prohibited. Likewise, the Florida panther also is listed by CITES in Appendix I. The Florida panther also is listed as a State and Federally Endangered Species, which means it is unlawful to kill or harass panthers, to possess skins, skulls, or any part of a panther, or to destroy habitat critical to the panther.

\section{THREATS}

Despite its protected status, the future of the jaguar is threatened by human activities even though the jaguar is threatened by human activities despite that the jaguar is legally protected in every country where they occur. Unfortunately, law enforcement varies among countries and is generally non-existent or very lax in most developing countries where jaguar are found. Jaguars are frequently killed to obtain their fur, for sport, or to protect livestock. The loss of forest habitat due to road construction, expanding agricultural, and other activities destroys, fragments, and degrades jaguar habitat in many regions throughout its range. With expanding human populations also comes increased hunting pressure on the preferred prey of jaguar in areas where year-round subsistence hunting is a way of life. All of these factors pose threats to the continued existence of this cat. Scientists and conservationists familiar with jaguar ecology are concerned that, without sufficient protection and management, the jaguar may disappear from most of its range by the end of this century.
Similar conservation concerns exist for the Florida panther, albeit on a more urgent scale. Expanding urban and agricultural development, compounded by a rapidly increasing human population has continued to destroy, fragment, and degrade habitat in southwest Florida needed by the panther for survival. The exact number of Florida panthers remaining is unknown, but suspected to be less than 100 animals. Indeed, the plight of the jaguar and the Florida panther represent only two examples in the worldwide decline in populations of large cats everywhere. The question for the future, therefore, is whether humans will allow large, wild cats to share the planet, or will they be eliminated everywhere, forever.

\section{ADDITIONAL READING}

Brown, David E. and Carlos A. Lopez. 2001. Borderland Jaguars: Tigres de la Frontera. The University of Utah Press. 170pp.

Hoogesteijn, Rafael and Edgardo Mondolfi. 1992. The Jaguar. Armitano Publishers C.A.

Swank, W. G. and J. G. Teer. 1989. Status of the jaguar - 1987. Oryx 23(1): 14-21

Web site: Wildlife Conservation Societys Save the Jaguar Program. http://wcs.org/7490/jag-index/

Web site: Florida Panther Net. http://www.panther.state.fl.us/ 